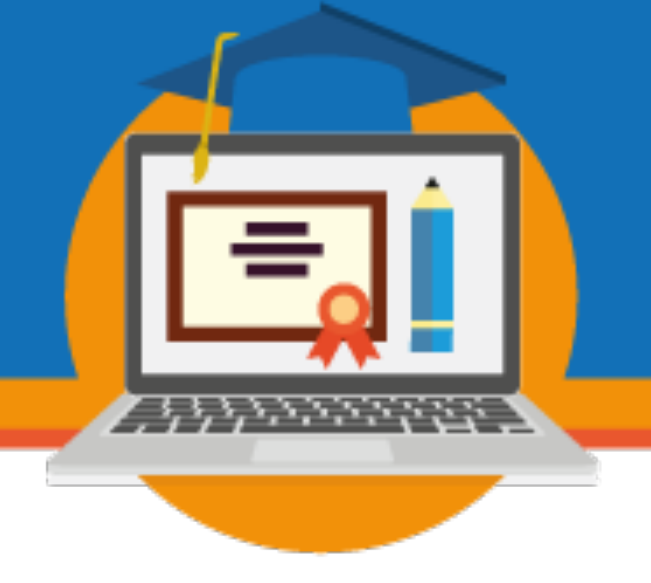

\title{
FORMAÇÃO CONTINUADA DE PROFESSORES E RECURSOS EDUCACIONAIS ABERTOS: ELEMENTOS DE INOVAÇÃO NA EDUCAÇÃO A DISTÂNCIA
}

\author{
Franciele Aparecida Henrique Taveira \\ francitaveira@gmail.com \\ Carina Elisabeth Maciel \\ carina22em@gmail.com \\ Daiani Damm Tonetto Riedner \\ daiani.riedner@ufms.br
}

\section{Universidade Federal de Mato Grosso do Sul}

Eixo 3: Tecnologias, mídias e processos inovadores na EaD

Resumo: O estudo teve como objetivo apresentar e analisar a proposta de criação de Recursos Educacionais Abertos na educação a distância como elemento de inovação no curso de Mídias na Educação oferecido pela Universidade Federal de Mato Grosso do Sul (UFMS), no período de 2017 a 2019. O trabalho é resultado de uma pesquisa qualitativa do tipo estudo de caso, que teve como base empírica o cadastro das propostas de criação do REA para o desenvolvimento do Trabalho Final de Curso (TFC), o Projeto Pedagógico do Curso e o regulamento. A concepção e a trajetória do curso demonstram o potencial de inovação que a criação de Recursos Educacionais Abertos no desenvolvimento do TFC trouxe para o processo formativo a distância, que teve foco na autoria e no desenvolvimento de conteúdos nas áreas em que os cursistas já atuavam, demonstrando que é possível e necessário pensar em práticas mais abertas que envolvam colaboração, criatividade e disseminação do acesso ao conhecimento.

Palavras-chave: Recursos Educacionais Abertos. Inovação. Práticas Pedagógicas. Educação a Distância. 


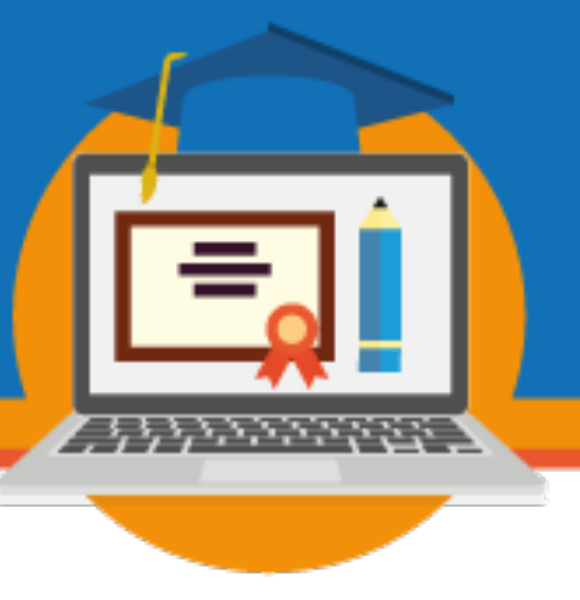

\section{Introdução ${ }^{1}$}

Na contemporaneidade, a educação tenta acompanhar as profundas mudanças ocorridas na sociedade, na qual a propagação das informações e a apropriação do conhecimento se desenvolvem de maneira rápida. Nesse contexto, os avanços tecnológicos e científicos vêm se alterando e, consequentemente, refletem nas práticas educativas na qual a educação a distância está inserida.

Essas transformações cada vez mais rápidas nos processos e nas práticas que envolvem a educação são comumente adjetivadas como "inovação", um termo que tem sido muito utilizado quando se trata do uso de tecnologias nos processos de aprendizagem. A ideia de inovação aponta para um cenário de movimento, que acompanha as mudanças da sociedade, muito atrelada ao desenvolvimento tecnológico, mas não dependente e exclusivo dele.

Conforme Riedner (2018, p. 37), “o conceito de inovação aparece relacionado com o conceito de mudança, como alterações que são realizadas de maneira progressiva”. É preciso considerar o que já existe, o contexto e os processos para que uma mudança se transforme em inovação de forma gradativa.

Nesse sentido, inovar na educação significa modificar as práticas pedagógicas com o intuito de criar novas estratégias de aprendizagem que atendam às necessidades dos estudantes, crianças e jovens nascidos e imersos na cultura digital. Pischetola et al (2019, p. 140) apontam que:

Para inovar a educação precisamos olhar para as tecnologias como parte da nossa cultura, refletir sobre as estratégias que nos permitem enfrentar a incerteza e a insegurança comuns em processos de mudança, e pensar sistemicamente a prática pedagógica.

Considerar a tecnologia como cultura é reconhecer que ela está imbricada nas nossas práticas sociais, culturais, econômicas e pedagógicas. Esse atrelamento tenciona cada vez mais mudanças de ordem estrutural, pedagógica e tecnológica nos processos educacionais, que já não se sustentam com práticas baseadas na instrução, transmissão e passividade dos estudantes.

${ }^{1}$ Este estudo faz parte da Pesquisa "Políticas de Expansão da Educação a Distância (EaD) no Brasil: Regulação, Qualidade e Inovação em Questão" e conta com apoio do Conselho Nacional de Desenvolvimento Científico e Tecnológico - CNPq - Brasil.

III SEMINÁRIO DE EDUCAÇÃO A DISTÂNCIA

Diálogos sobre EaD e uso das TDIC na educação: regulamentação em tempos recentes 3 a 6 de novembro de 2020 - Brasília/DF - Online 


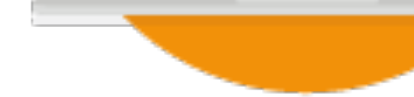

Cada vez mais, as tecnologias imersivas estão tomando a palma das nossas mãos, por meio da realidade virtual e aumentada, da gamificação, da robótica e da impressão 3D. O acesso à informação é instantâneo e recebemos conteúdos dos mais variados tipos e formatos a todo momento. Esse movimento dinâmico requer, cada vez mais, a integração de estratégias didáticas e metodológicas que considerem a capacidade de criação, autoria e pesquisa dos estudantes, favorecendo o desenvolvimento de diferentes habilidades e do pensamento crítico.

É nesse contexto que os Recursos Educacionais Abertos (REA) têm ganhado cada vez mais espaço, mas antes de falar sobre REA é preciso pensar um pouco sobre o conceito de Educação Aberta, pois é nesse contexto e nessa discussão que se inserem os REA.

O movimento para uma Educação Aberta é uma tentativa de buscar alternativas sustentáveis para algumas das barreiras evidentes no que tange ao direito a uma educação de qualidade. Nessa perspectiva, o conceito de "abertura" não é necessariamente dependente de desenvolvimentos tecnológicos, e antecede a popularização de dispositivos digitais, da internet e da web, mas pode ser fortalecida pelas novas mídias. (CURSO REA, 2018).

É um movimento mundial da educação que busca a democratização da aprendizagem por meio do livre acesso ao conhecimento com uso de práticas abertas, inovadoras e inclusivas, em todos os níveis de ensino, de maneira formal ou informal, presencialmente ou online. (SANTOS, 2012). Atualmente, Educação Aberta também se relaciona ao $4^{\circ}$ Objetivo do Desenvolvimento Sustentável, que enfatiza qualidade e equidade.

Nesse contexto, os REA se caracterizam como materiais de ensino, aprendizagem e pesquisa disponibilizados na internet e por práticas de compartilhamento desses materiais para produção colaborativa que, perante o uso das licenças abertas, permitem o acesso, o reuso, a adaptação e a redistribuição de conteúdos nos mais diversos suportes de mídia.

O presente trabalho tem como objetivo analisar a proposta de criação de Recursos Educacionais Abertos no âmbito do Trabalho Final de Curso, do Curso de Pós-graduação Lato Sensu em Mídias na Educação, ofertado a distância no período de 2017 a 2019, pela Faculdade de Educação da Universidade Federal de Mato Grosso do Sul (UFMS) em parceria com a Universidade Aberta do Brasil (UAB). Os objetivos específicos são: 1) Compreender a 


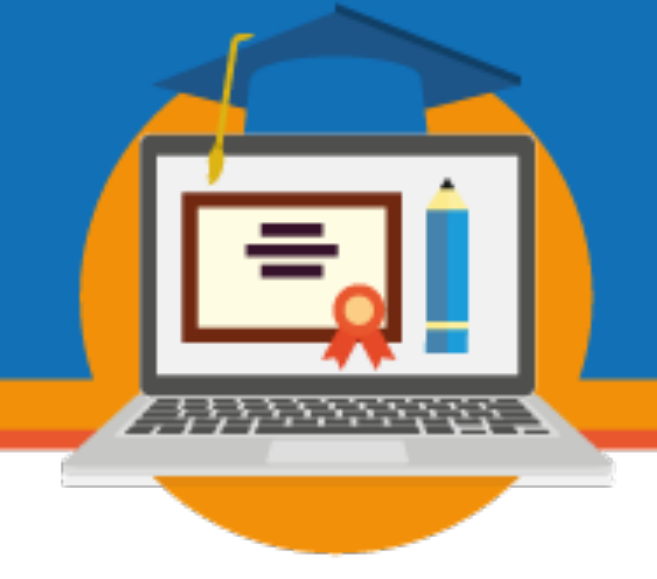

importância dos REA para o processo formativo na educação a distância; 2) Apresentar a proposta de criação de REA no trabalho final do curso de Mídias na Educação.

A base empírica deste trabalho foi construída a partir de uma pesquisa bibliográfica sobre a temática, além de consultas nos documentos do curso de especialização e no cadastro da proposta do trabalho final de curso realizada pelos alunos por meio de um Formulário do Google.

A investigação de caráter qualitativo se caracteriza como um estudo de caso. $\mathrm{Na}$ historicidade desse objeto, as análises construídas a partir do material empírico se interrelacionam com as reflexões e experiências de uma das autoras, que atuou na tutoria a distância do Curso de pós-graduação em Mídias na Educação e vivenciou na prática o processo de criação dos cursistas.

\section{Recursos Educacionais Abertos e Licenças Abertas: conceitos e características}

Partindo do princípio da democratização do acesso ao conhecimento por meio das tecnologias digitais, que facilitam o acesso, produção e difusão do conhecimento, a educação aberta visa permitir o acesso a oportunidades e experiências de aprendizagem que não restringem ao espaço físico da sala de aula, mas que se expande de forma exponencial com o acesso à internet.

Na perspectiva de Amiel (2012, p. 19), a educação aberta significa:

Fomentar (ou ter à disposição) por meio de práticas, recursos e ambientes abertos, variadas configurações de ensino e aprendizagem, mesmo quando essas aparentam redundância, reconhecendo a pluralidade de contextos e as possibilidades educacionais para o aprendizado ao longo da vida.

Sendo assim, as práticas na educação aberta poderão ocorrer dependendo do contexto em que está inserida. No Brasil, a Educação Aberta e os Recursos Educacionais Abertos caminharam junto com a expansão da educação a distância, principalmente no setor público, por meio da UAB.

Em 2016, após uma formação interna com o Instituto Educa Digital e a Cátedra de 
Educação Aberta da Unesco, a UAB CAPES modificou o seu termo de compromisso para os bolsistas, incluindo a necessidade de assinalar umas das licenças Creative Commons para disponibilização de todo material produzido no âmbito da atuação do bolsista.

Esse movimento fomentou a criação e expansão do Portal de Recursos Educacionais Abertos da CAPES, o eduCAPES ${ }^{2}$. Esse repositório engloba em seu acervo milhares de objetos de aprendizagem, incluindo textos, livros didáticos, artigos de pesquisa, teses, dissertações, videoaulas, áudios, imagens e quaisquer outros materiais de pesquisa e ensino que estejam licenciados de maneira aberta, publicados com autorização expressa do autor ou ainda que estejam sob domínio público.

Nesse contexto, a educação aberta juntamente com o uso dos Recursos Educacionais Abertos (REA), tem como objetivo ampliar as possibilidades de ensino-aprendizagem em vários ambientes impulsionando o acesso ao conhecimento e tornando os estudantes protagonistas de seu aprendizado e produtores de conteúdo.

Demo (2010,p. 868) completa que "na prática, se quisermos aluno autor, antes é preciso inventar docente autor". Observa-se a necessidade da ruptura dos professores gerando seus próprios materiais e criando a cultura do compartilhamento por meio dos REA, tendo assim uma forma prática e inovadora na educação.

De acordo com o Fórum da Organização das Nações Unidas para a Educação, a Ciência e a Cultura (Unesco), no ano de $2002^{3}$ foi lançado o termo que define o significado dos Recursos Educacionais Abertos (REA) ou open educational resourses (OER).

Em uma breve retrospectiva histórica dos REA que tem na sua origem o software livre, observamos que perpassa nas políticas públicas educacionais para a sua efetivação e divulgação, juntamente com algumas instituições como a Fundação William e Flora Hewlett, uma das principais financiadoras das ações desse movimento. Já a UNESCO teve sua participação na Declaração da Cidade do Cabo em 2007 com o objetivo de acelerar os esforços para ascensão dos recursos, tecnologias e práticas abertas definindo procedimentos para a

${ }^{2}$ Disponível em: https://educapes.capes.gov.br/.

${ }^{3}$ Disponível em: REA. Acesso em: 03 jan, 2020.

III SEMINÁRIO DE EDUCAÇÃO A DISTÂNCIA

Diálogos sobre EaD e uso das TDIC na educação: regulamentação em tempos recentes 3 a 6 de novembro de 2020 - Brasília/DF - Online 


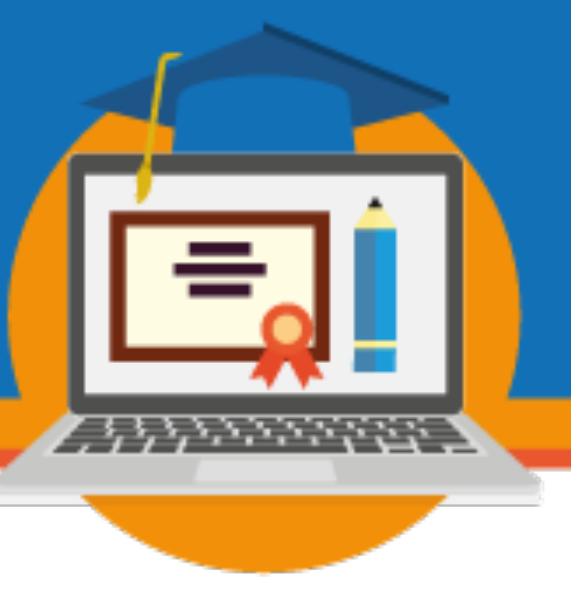

comunidade escolar (MAZZARDO, 2018).

No ano de 2012 foi realizada no Congresso Mundial sobre os Recursos Educacionais Abertos, coordenados pela UNESCO e Commonwealth of Learning (COL), a elaboração da Declaração de Paris sobre REA, com recomendações para os Estados sobre o fomento e a adoção de tais recursos (MAZZARDO, 2018). O documento caracteriza os REA como:

[...] materiais de ensino, aprendizado, e pesquisa em qualquer suporte ou mídia, que estão sob domínio público, ou estão licenciados de maneira aberta, permitindo que sejam utilizados ou adaptados por terceiros. O uso de formatos técnicos abertos facilita o acesso e o reuso potencial dos recursos publicados digitalmente. Os REA podem incluir cursos completos, partes de cursos, módulos, livros didáticos, artigos de pesquisa, vídeos, testes, software, e qualquer outra ferramenta, material ou técnica que possa apoiar o acesso ao conhecimento. (UNESCO, 2012, p. 1).

Em âmbito nacional, temos o projeto de Lei $\mathrm{n}^{\circ} 1.513$ de 2011 de autoria do deputado Paulo Teixeira, substitutivo no ano de 2018, que "dispõe sobre os procedimentos a serem observados pelo Poder Público, na produção e na subvenção à produção de Recursos Educacionais Abertos - REA”(BRASIL, 2018).

Outros documentos que abordam os REA são: a) Plano Nacional de Educação (PNE) vigente no período de 2014 até 2024, presente nas metas cinco e sete sobre qualidade na educação básica que fomenta o incentivo aos REA; b) o Decreto Municipal no Estado de São Paulo (52.681/11); c) Projetos de Lei Estadual do PR (185/2014) e do DF (1832/2014) que tratam sobre o licenciamento das obras intelectuais. (GONSALES, 2015).

Resumidamente, os REA podem ser trabalhados em três princípios básicos: a) produção de conteúdo para ensino, aprendizagem ou pesquisa; b) atribuição de uma licença aberta; c) compartilhamento desses conteúdos.

Os REA também apresentam suas particularidades que se apoiam em algumas liberdades mínimas que são conhecidas popularmente como 5Rs, organizadas pelo pesquisador americano David Wiley (SEBRIAM; MARKUN; GONSALES, 2017), as cinco liberdades se consolidaram como um círculo virtuoso de criação e colaboração.

Reter (retain) - direito de fazer e possuir cópias dos recursos; reutilizar (reuse) - direito de usar o conteúdo de formas variadas; rever (revise - direito de adaptar, ajustar, modificar ou alterar o conteúdo; remix (remix) - direito de combinar o conteúdo original ou adaptado com outro conteúdo aberto, com 


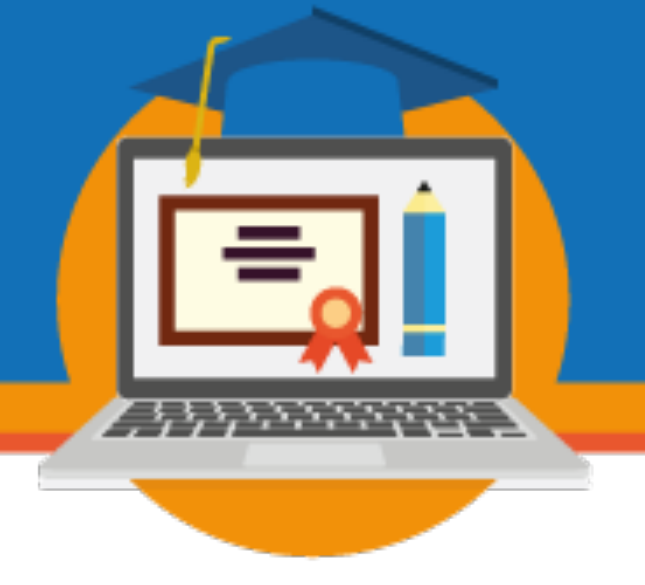

a finalidade de criar um novo recurso; redistribuir (redistribute) - o direito de compartilhar cópias do conteúdo original revisado e/ou remixado (MAZZARDO; NOBRE; MALLMANN, 2017, p.30).

Diante de todas essas vantagens dos REA, encontramos alguns obstáculos que precisam ser superados. O principal deles é o conhecimento e sobre direitos autorais e licenças abertas. Muitos professores desconhecem a Lei de Direitos autorais e também as possibilidades de atribuição de licenças abertas nos seus materiais.

$\mathrm{O}$ fato de encontrar qualquer conteúdo na internet de forma gratuita e ter a possibilidade fácil de download, não significa que esse conteúdo é aberto para uso. Para que as liberdades de uso sejam comunicadas de forma acessível aos usuários, é necessário a atribuição de licença abertas. E ainda há grande desconhecimento da comunidade acadêmica sobre essas possibilidades (HILU; TORRES; BEHRENS, 2015).

Com o emaranhado de informações que circulam na internet e a facilidade que temos de disponibilizar conteúdos online, as licenças abertas ajudam os autores a informar sobre as liberdades de uso desses materiais. Os repositórios de REA têm sido uma alternativa viável e segura para esse tipo de disponibilização.

As licenças mais utilizadas são as Creative Commons, conhecidas pela sigla (CC). O Creative Commons é uma organização sem fins lucrativos que certifica o direito do autor permitindo-lhe expressar as regras de uso do 5R. Existem seis tipos de licenças:

CC BY- Atribuição; CC BY SA- atribuição e compartilhamento igual; CC BY NC - atribuição e não comercial; CC BY NC AS - atribuição, não - comercial e compartilhamento igual; CC BY NOatribuição e não- derivação; CC BY-NC-ND atribuição- não -comercial-sem derivações (SEBRIAM; MARKUN; GONSALES, 2017, p. 26).

Nessa perspectiva, cabe ao autor escolher a melhor licença a ser atribuída no seu REA. Concomitantemente temos os Direitos Morais e Patrimoniais estabelecidos na Lei de Direitos Autorais Brasileira (Lei 9610/98) no artigo 29, onde "determina que todas as obras estão automaticamente protegidas do uso e reprodução, incluindo comercialização e edição". (SEBRIAM; MARKUN; GONSALES, 2017).

Com todas as suas particularidades, os REA se caracterizam como conteúdos e materiais em qualquer suporte de mídia, disponibilizados de forma digital (online ou offline) ou até 

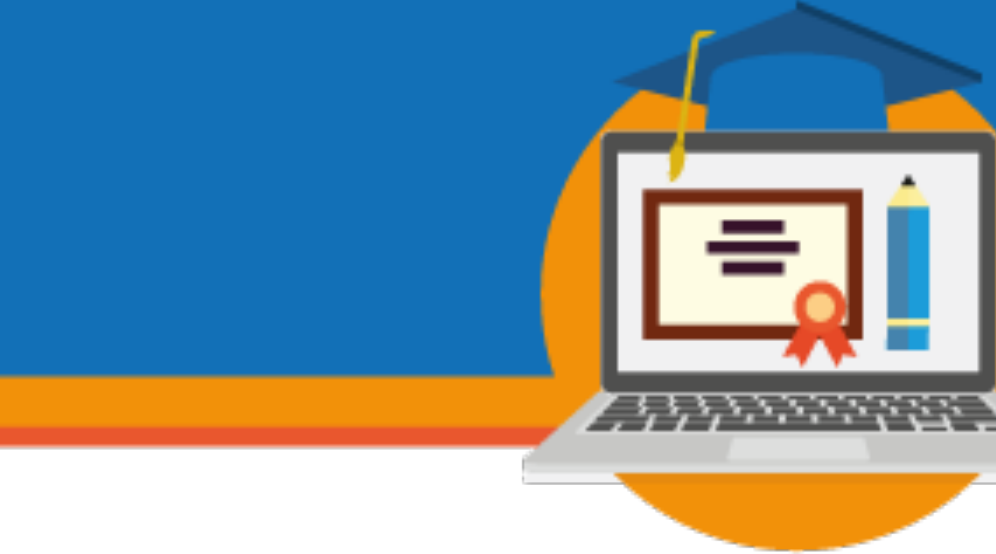

mesmo impresso, que podem ser utilizados para fins de ensino, aprendizagem ou pesquisa e que, dependendo da licença atribuída pelo autor, podem ser utilizados, recombinados e compartilhados por outras pessoas como forma de expansão do acesso ao conhecimento, bem como de melhoria das práticas educacionais.

\section{A criação de REA no curso de Mídias na Educação: potencial de inovação na formação continuada de professores}

O curso de Pós-graduação Lato Sensu em Mídias na Educação, foi oferecido a distância pela Faculdade de Educação da UFMS em parceria com a UAB no período de novembro de 2017 a agosto de 2019. O documento que normatiza o curso é a Resolução COPP n ${ }^{\circ} 195$ de 11 de agosto de 2017.

De acordo com artigo $2^{\circ}$ da Resolução COPP $n^{\circ} 195$ o objetivo do curso de Mídias na Educação é "capacitar e instrumentalizar os professores do ensino fundamental e médio da rede pública municipal e estadual de Mato Grosso do Sul para o uso crítico e criativo das mídias e tecnologias digitais na prática pedagógica” (BRASIL, 2017, p. 8).

O gráfico a seguir demonstra que a maioria dos alunos estavam atuando na docência no período da oferta do curso. Apenas 18,9\% informou não estar atuando e apenas quatro cursistas não tinham nenhuma experiência de docência na educação básica. 


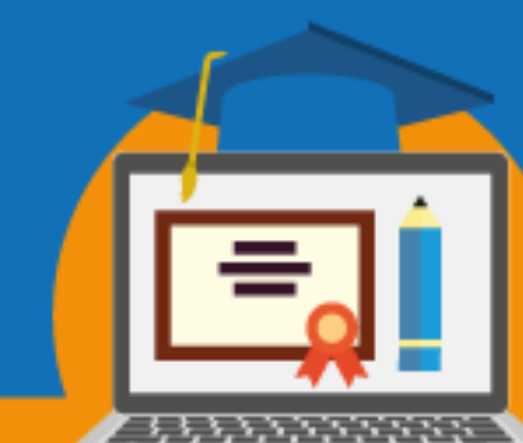

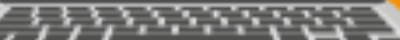

Gráfico 1: Tempo de atuação profissional dos cursistas

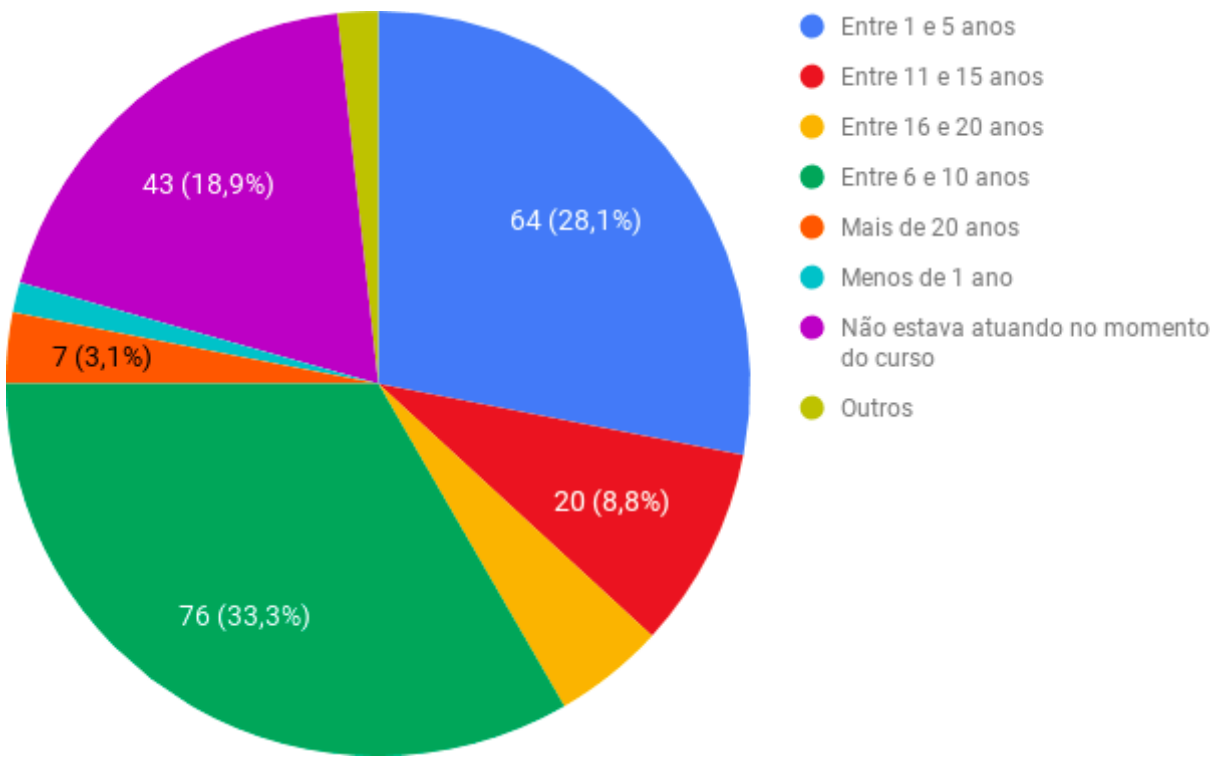

Fonte: Curso de Mídias na Educação (2019).

A organização didática do curso está prevista no artigo $8^{\circ}$ da mesma resolução, na qual “a carga horária a distância dos módulos do Curso será oferecida por meio das tecnologias da educação a distância no Ambiente Virtual de Aprendizagem - Moodle, com apoio da Secretaria Especial de Educação a Distância e Formação de Professores” (RESOLUÇÃO COPP, 2017, p. $8)$.

A proposta pedagógica do curso em análise (oferta de 2017) foi organizada em oito módulos de 45 horas, totalizando 360 horas de curso e 24 créditos. O curso partiu de um módulo de ambientação para educação a distância, compreensão sobre as relações da cultura digital com a escola, sobre o uso de tecnologias no contexto da prática pedagógica, depois o planejamento e produção de conteúdos digitais, com um módulo específico para produção de vídeos.

$\mathrm{Na}$ sequência foram abordadas diversas estratégias didáticas no âmbito do ensino híbrido com ênfase na sala de aula invertida. Depois um módulo específico para tecnologias digitais na educação especial, que era uma necessidade bem visível e com pouca oferta nesta área de formação. E por último o módulo que englobou a metodologia de pesquisa e o 


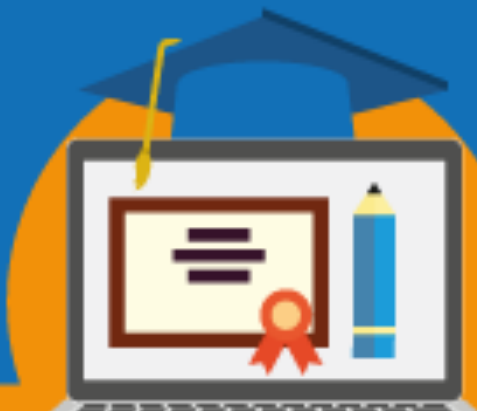

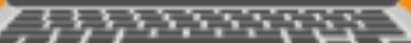

desenvolvimento de projetos, cujas discussões encaminharam os alunos para os recursos educacionais abertos.

Dos 350 cursistas matriculados no curso, 228 conseguiram cumprir todas as disciplinas e cadastrar a proposta do TFC. O gráfico a seguir mostra a organização dos cursistas por polo.

Gráfico 2: Quantidade de cursistas por polo

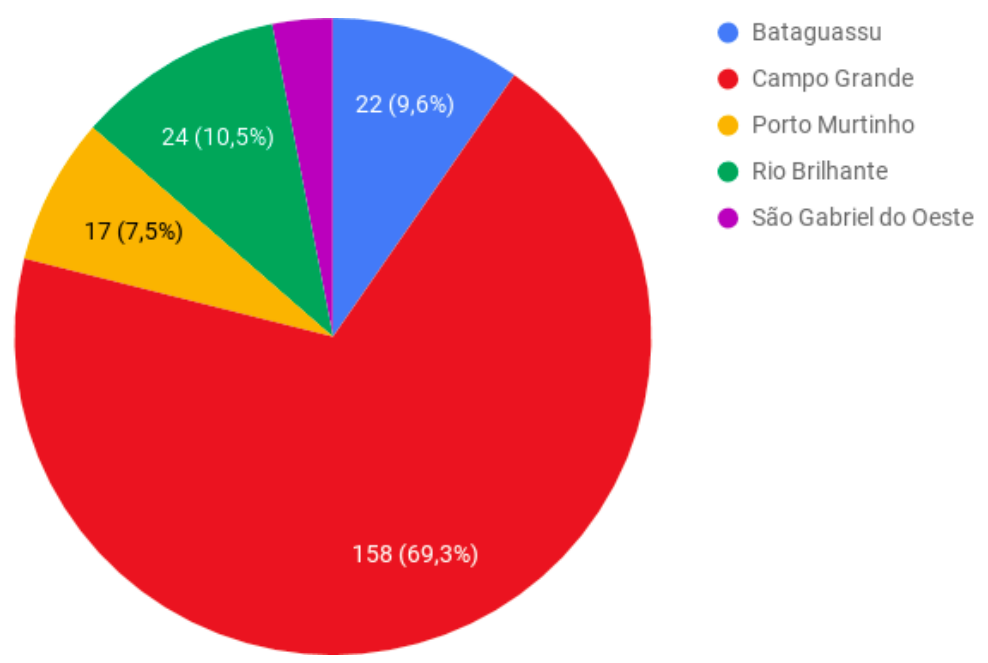

Fonte: Curso de Mídias na Educação (2019).

Muitas tratativas internas foram necessárias para implementação do modelo de Trabalho Final de Curso baseado na produção de um conteúdo digital. Isso aconteceu devido ao engessamento do regulamento interno da instituição para ofertas de cursos de especialização. Após algumas idas e vindas do processo com as devidas justificativas, ficou definido no regulamento do curso que o Trabalho Final de Curso seria a produção de um conteúdo digital no formato de Recursos Educacionais Abertos, sendo obrigatória a atribuição de uma Licença Creative Commons pelos autores.

Dentro do modelo de financiamento da UAB, para cada 25 alunos ativos, o curso tem direito a um tutor responsável, que pode ser tutor presencial ou tutor a distância, dependendo da metodologia de oferta do curso. Iniciamos a oferta em novembro de 2017 com 14 tutores que foram selecionados por meio de Edital e esse número foi diminuindo de forma gradativa,

\section{SEMINÁRIO DE EDUCAÇÃO A DISTÂNCIA}




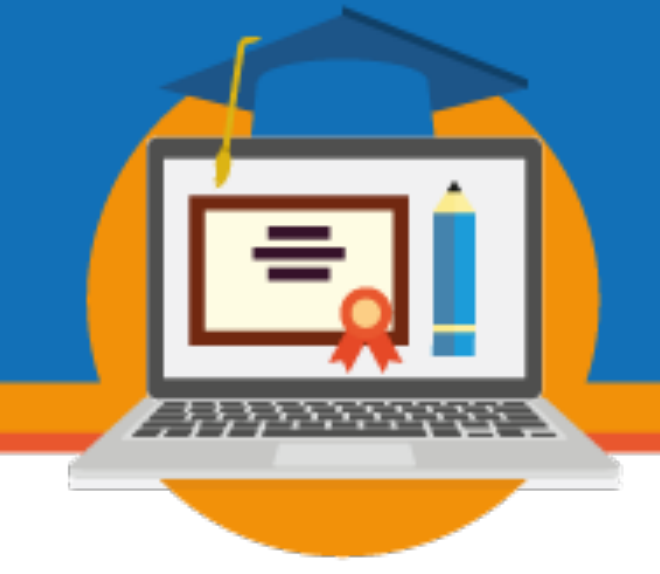

na medida em que os alunos foram evadindo. Na oferta de cada disciplina, aconteceu um encontro presencial nos cinco polos com a presença de um professor. Foram 22 professores atuando, sendo 14 professores voluntários.

No período de execução do último módulo do curso, iniciamos a preparação dos alunos para a etapa do TFC e realizamos duas webconferências explicando como seria o processo. Posteriormente foi aberto um Edital de Seleção de Professores Orientadores, no qual foram aprovados 16 professores. E devido à grande demanda de orientação (223 alunos cadastrados para o TFC) abrimos um cadastro de orientadores voluntários e juntamos ao grupo mais 28 professores, totalizando 44 orientadores.

No período do TFC, os alunos foram organizados em grupos de orientação e distribuídos entre os 8 tutores que ainda estavam atuando. Durante os 5 meses de trabalho, eles tiveram apoio da tutoria e do professor orientador para realização das etapas de execução do trabalho. O processo de elaboração/criação do REA foi organizado em seis etapas: 1) Versão 1 do Projeto de TFC; 2) Versão 2 do Projeto de TFC; 3) Roteiro de Criação do REA; 4) Versão 1 do REA; 5) Versão 2 do REA; 6) Versão Final do REA e Relatório de Criação do REA.

Para a produção dos REA, a coordenação do curso disponibilizou aos cursistas alguns roteiros de criação com o objetivo de organizar o processo de produção do REA. Para dar esse direcionamento, foram escolhidos dezesseis tipos de material, cujos roteiros eram diferenciados. O gráfico a seguir demonstra a escolha dos cursistas pelos materiais que seriam produzidos. 


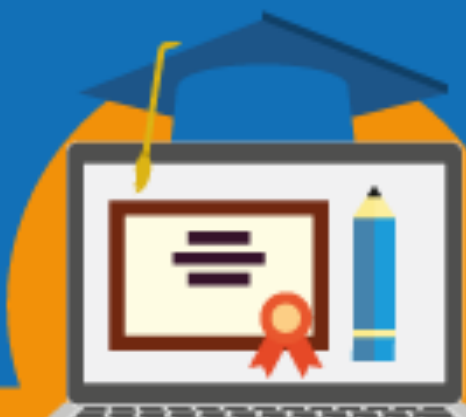

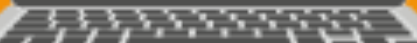

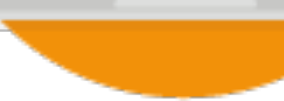

Gráfico 3: Tipos de recursos escolhidos pelos cursistas para produção do REA

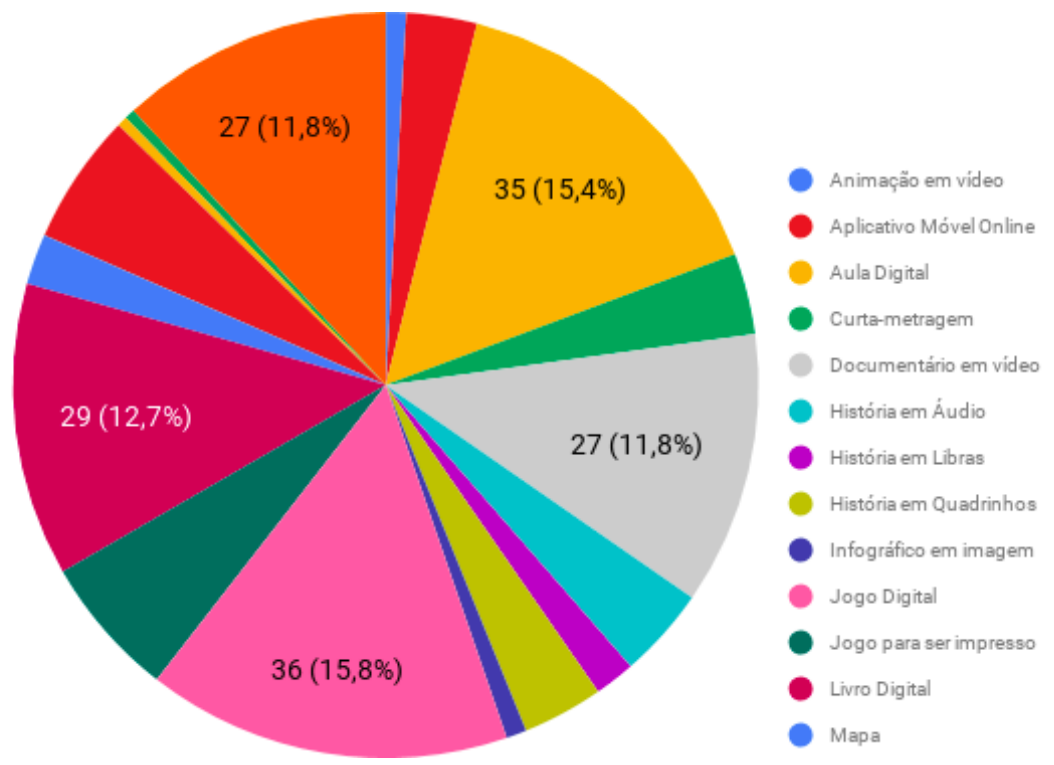

Fonte: Curso de Mídias na Educação (2019).

A maioria dos cursistas concentrou sua escolha em cinco tipos de recursos: a) jogo digital, que poderia ser produzido em qualquer plataforma online; b) aula digital, que poderia ser produzida no Prezi Classic ou no Google Apresentações; c) Livro Digital, que poderia ser produzido em qualquer editor de texto e depois diagramado e disponibilizado em PDF; d) Documentário em vídeo, que poderia ser produzido em qualquer editor de vídeo; e) Aplicativo Móvel, que poderia ser produzido numa fábrica de Apps online ou apresentação do protótipo em telas.

No cadastro da proposta do REA, os cursistas também tiveram que indicar a área do conhecimento, a unidade de conteúdo, o objetivo geral, o resumo da proposta e um título provisório, para que os orientadores pudessem escolher os trabalhos que poderiam orientar. Houve uma grande diversidade de áreas e conteúdos, e a maioria dos cursistas escolher produzir materiais para o Ensino Fundamental II e I, respectivamente, conforme mostra o gráfico a seguir. 


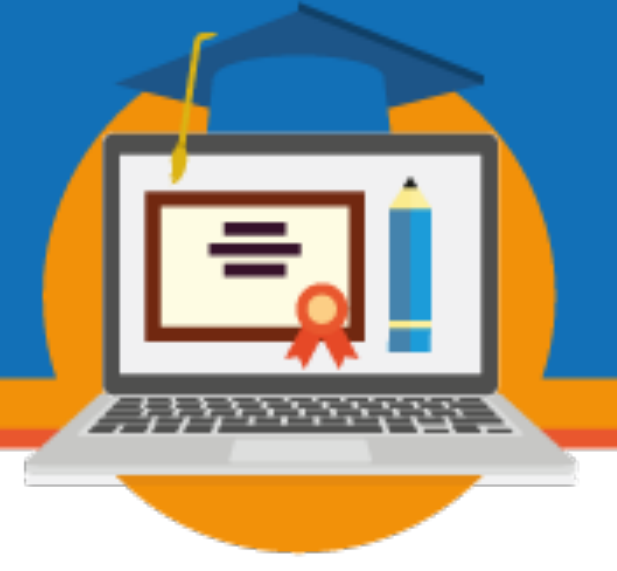

Gráfico 5: Indicação do Nível de Ensino dos REA

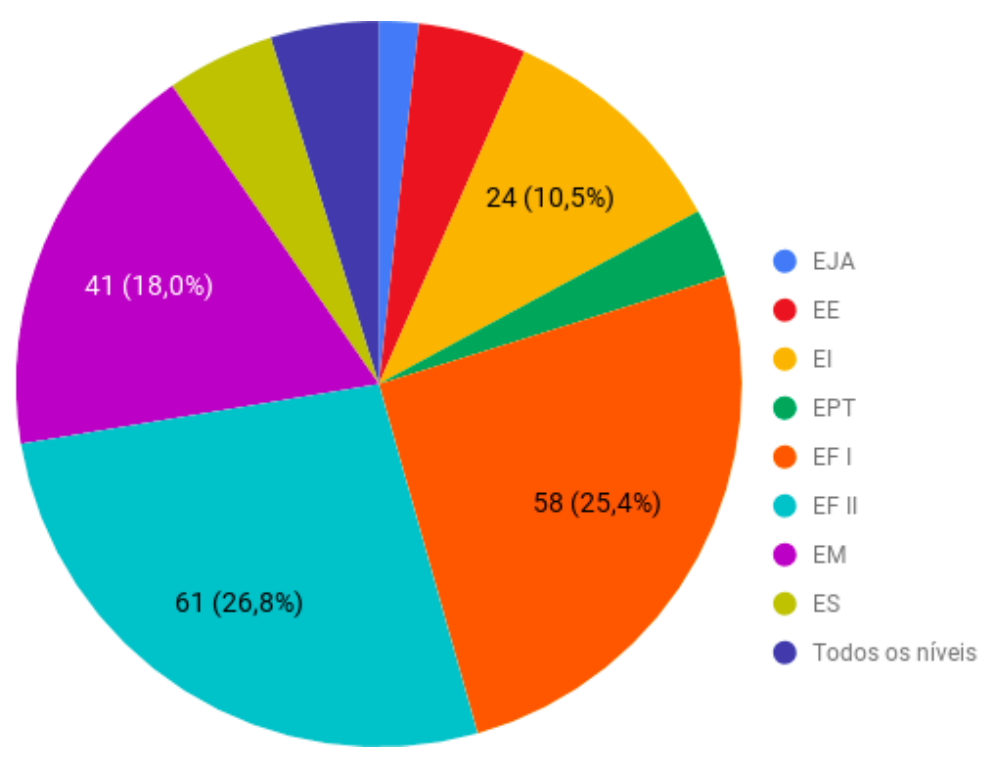

Fonte: Curso de Mídias na Educação (2019).

Além da criação do REA, os cursistas tiveram que preencher o "Relatório de Criação do REA”, que teve como objetivo levantar dados mais objetivos e subjetivos sobre o processo de criação do REA e também uma tentativa para que os alunos compreendessem e fizessem o exercício de descrever o uso educacional e pedagógico do material que eles haviam produzido. O documento foi organizado da seguinte forma: 1) Ficha técnica do REA; 2) Contextualização da proposta do REA; 3 ) Metodologia de produção do REA; 4) Estratégias didáticas de utilização do REA; 5) Reflexões finais e 6) Referências.

Em relação à atribuição das licenças Creative Commons nos materiais, a escolha dos cursistas ficou concentrada em quatro das seis possibilidades que foram colocadas no formulário. De uma forma geral, essas escolhas demonstram o entendimento dos cursistas sobre o conceito de REA, pois as licenças mais utilizadas são as que preconizam um conceito maior de abertura. O gráfico a seguir mostra essa escolha. 


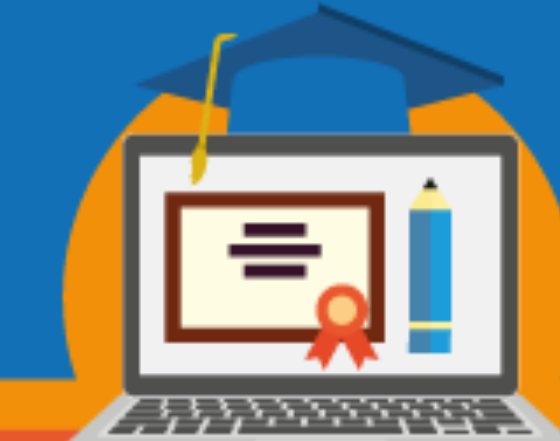

Gráfico 4: Licenças Creative Commons escolhidas para os materiais

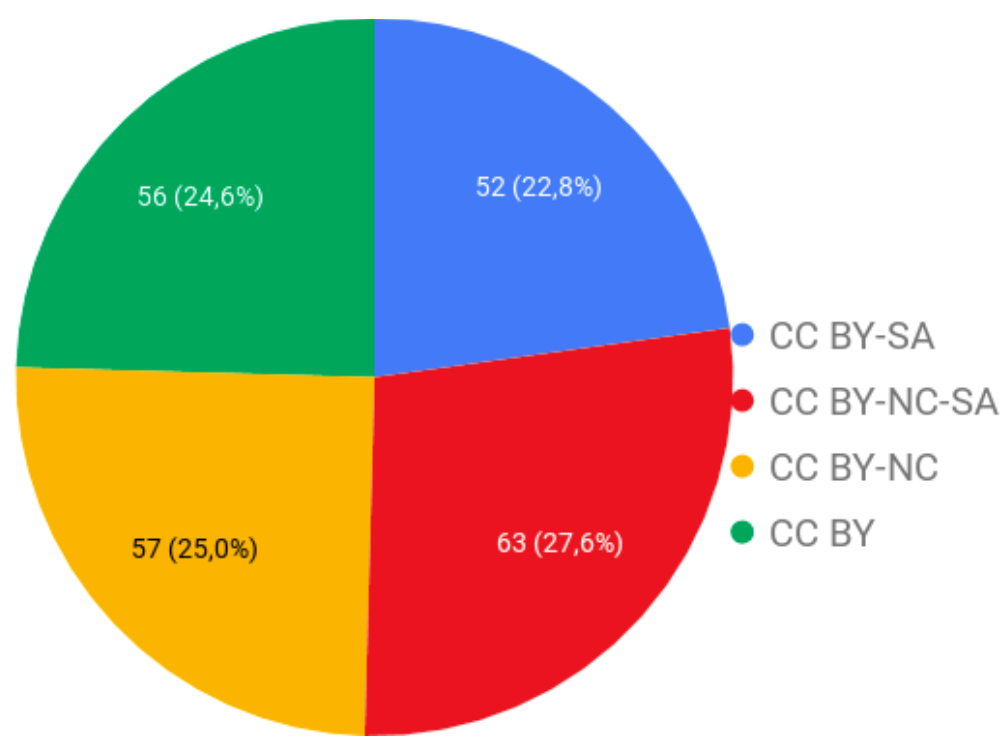

Fonte: Curso de Mídias na Educação (2019).

Em setembro de 2019, a Secretaria Especial de Educação a Distância promoveu o “IntegraEaD”, evento científico em que os cursistas tiveram a oportunidade de divulgar seus trabalhos. O evento aconteceu de forma híbrida, presencial e online, e teve como foco a "Formação e práticas pedagógicas híbridas: diálogos entre tecnologias, currículo, diversidade e políticas".

O curso de Mídias na Educação em nível de especialização já havia sido oferecido três vezes na UFMS, nos anos de 2009, 2011 e 2013, além das ofertas em nível de extensão. A oferta de 2017 foi pioneira na mudança estratégica do Trabalho Final de Curso para oportunizar aos cursistas uma experiência de formação integrada com a proposta pedagógica do curso e com as necessidades de formação dos professores que se vêem diante da necessidade de organizar e produzir materiais de ensino e aprendizagem no dia a dia do seu trabalho pedagógico.

Além disso, o curso foi o primeiro no sistema UAB a organizar esse tipo de trabalho 


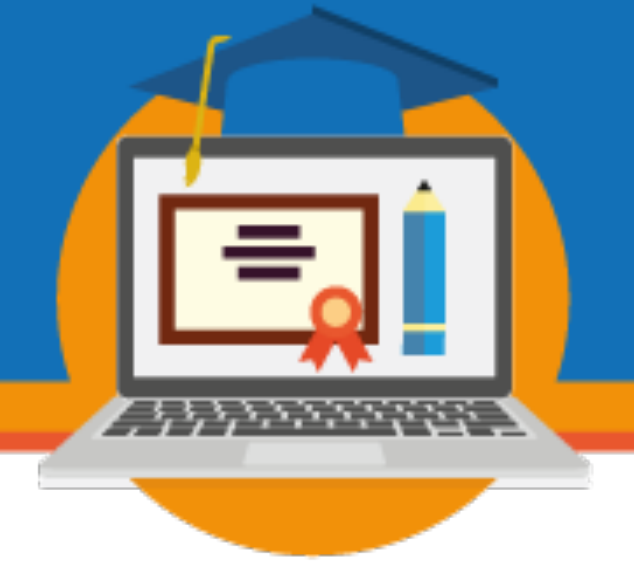

final de curso voltado prioritariamente para produção de Recursos Educacionais Abertos. Os cursistas foram orientados a publicar seus materiais no repositório de REA da Capes, o eduCapes, para dar visibilidade às produções e oportunizar que outros professores conheçam essa experiência de formação.

\section{Considerações Finais}

Esse trabalho teve como foco analisar a proposta de criação de Recursos Educacionais Abertos no âmbito do Trabalho Final de Curso, do Curso de Pós-graduação Lato Sensu em Mídias na Educação. Como desdobramento do objetivo geral, o texto buscou trazer a compreensão sobre a importância dos REA para o processo formativo na educação a distância, bem como apresentar a proposta de criação de REA no trabalho final do curso de Mídias na Educação como um elemento de inovação na formação continuada a distância.

Para Riedner (2019) a inovação é sempre contextual, pois requer que as estratégias sejam pensadas com base no que já existe na instituição, considerando o grupo de trabalho que se envolve com a proposta. A autoria indica que construção de práticas inovadoras depende do

[...] contexto organizacional da instituição, ou seja, um contexto que tenha infraestrutura tecnológica, recursos humanos para apoio ao professor e uma cultura organizacional favorável pode impulsionar os professores a desenvolverem práticas inovadoras com uso de tecnologias. (RIEDNER, 2019, p. 46).

Nesse sentido, o curso de Mídias na Educação construiu uma proposta inovadora no contexto institucional, que foi possível pelas condições pedagógicas, tecnológicas e administrativas, favoráveis à mudanças inclusive das normativas internas, que permitiram a compreensão da importância do processo criativo no curso cuja proposta pedagógica preconiza a autoria e a colaboração.

Essa experiência de formação traz à tona a necessidade de melhor compreensão sobre o conceito de educação aberta, que envolve práticas de produção e disponibilização de REA e que preconizam a autoria, a colaboração, o compartilhamento e o acesso ao conhecimento de 


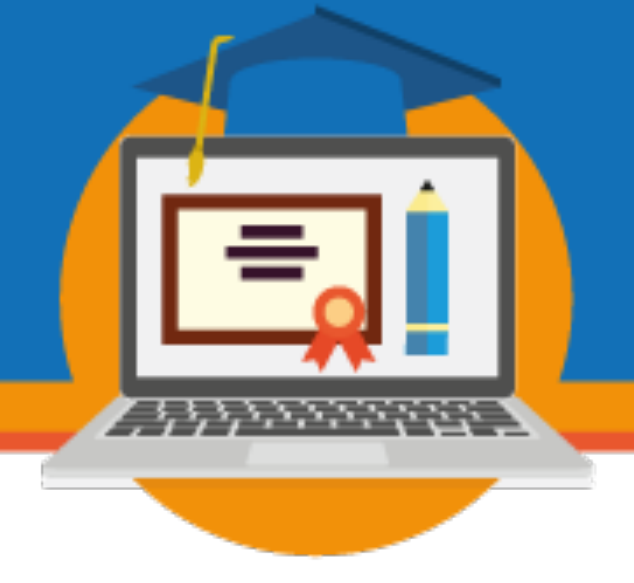

forma abrangente. Esses valores e práticas ainda estão longe de ser incorporados nos processos formativos, independente da modalidade de ensino, se é que ainda seja necessário fazer a dicotomia entre presencial e a distância.

O que percebemos na construção desse estudo é a necessidade de conhecimento, discussão e incorporação dessas práticas no dia a dia do trabalho pedagógico, além da difusão de experiências e das políticas públicas sobre REA, para que cada vez mais os professores e as instituições sejam capazes de fomentar práticas e tecnologias que estimulem a criatividade e tragam inovação para o ensino, aprendizagem e pesquisa em todos os níveis de ensino e em todas as áreas do conhecimento.

\section{Referências}

AMIEL, Tel. Educação aberta: configurando ambientes, práticas e recursos educacionais. In: SANTANA, Bianca; ROSSINI, Carolina; PRETTO, Nelson De Lucca. (Org.). Recursos Educacionais Abertos: práticas colaborativas políticas públicas. 1. Ed. São Paulo: Casa da Cultura Digital, 2012.p. 17-33.

BRASIL. Projeto de Lei Federal $N^{\mathbf{0}}$ 1513/2011. Dispõe sobre os procedimentos a serem observados pelo Poder Público na produção e na subvenção à produção de Recursos Educacionais Abertos - REA Disponível em: http://gg.gg/gma5p. Acesso em: 04 jan. 2020.

CREATIVE COMMONS. Sobre as Licenças. Disponível em: https://br.creativecommons.org/licencas/. Acesso em: 12 out. 2019. 


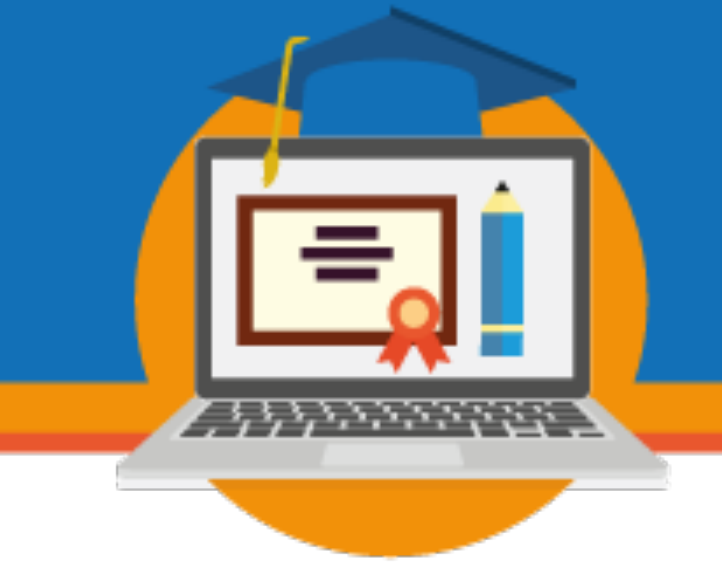

CURSO REA. Curso Educação Aberta e Recursos Educacionais Abertos. Iniciativa Educação Aberta, 2018. Disponível em: https://cursos.aberta.org.br/login/index.php. Acesso em: 11 out. 2019.

DEMO, Pedro. Rupturas urgentes em educação. Revista Ensaio: Avaliação e Políticas Públicas em Educação. Rio de Janeiro, v. 18, n. 69, p. 861-872, out./dez. 2010. Disponível em: http://www.scielo.br/pdf/ensaio/v18n69/v18n69a11.pdf. Acesso em: 10 jan 2020.

EDUCAÇÃO ABERTA. Recursos Educacionais Abertos (REA): um caderno para professores. Campinas, 2013. Disponível em: http://educacaoaberta.org/cadernorea. Acesso em: 11 out. 2019.

GONSALES, Priscila. Educação aberta e recursos educacionais abertos na política pública brasileira. Digital Rights, v. 6, n. 24 jul. 2015. Disponível em: https://www.digitalrightslac.net/pt/educacion-abierta-y-recursos-educativos-abiertos-en-la politica-publica-brasilenal. Acesso em: 04 jan. 2020.

HILU, Luciane; TORRES, Patricia Lupion; BEHRENS, Marilda Aparecida. REA (RECURSOS EDUCACIONAIS ABERTOS) - CONHECIMENTOS E (DES)CONHECIMENTOS. Revista e-Curriculum, v. 13, n. 01 p. 130 - 146, jan./mar, 2015.Disponível em: http://revistas.pucsp.br/index.php/curriculum. Acesso em: 03 jan. 2020.

MAZZARDO, Mara Denize; NOBRE, Ana Maria Ferreira; MALLMANN Elena Maria. Recursos Educacionais Abertos: Acesso Gratuito ao Conhecimento? Revista EaD em Foco, v. 7, n.1, p. 27-36, abr. 2017. Disponível em: https://eademfoco.cecierj.edu.br/index.php/Revista/article/view/446. Acesso em: 04 jan. 2020.

MAZZARDO, Mara Denize. Recursos Educacionais Abertos: inovação na produção de materiais didáticos dos professores do Ensino Médio. Lisboa,2018, 280. Tese de Doutorado Departamento de Educação a Distância e Elearming, Universidade Aberta,2018. Disponível em: https://repositorioaberto.uab.pt/bitstream/10400.2/7788/1/TD MaraMazzardo.pdf. Acesso em: 20 jan 2020.

PISCHETOLA, Magda. et al. Tecnologias, pensamento sistêmico e os fundamentos da inovação pedagógica. Curitiba: Editora CRV, 2019.

RIEDNER, Daiani Damm Tonetto. Tecnologias digitais na formação inicial de professores: percepções dos estudantes sobre a inovação pedagógica. Perspectivas em Diálogo, Naviraí, v . 7, n. 12 (especial), p. 28-50, 2019. Disponível em: https://periodicos.ufms.br/index.php/persdia/article/view/9169. Acesso em: 16 fev. 2020. 


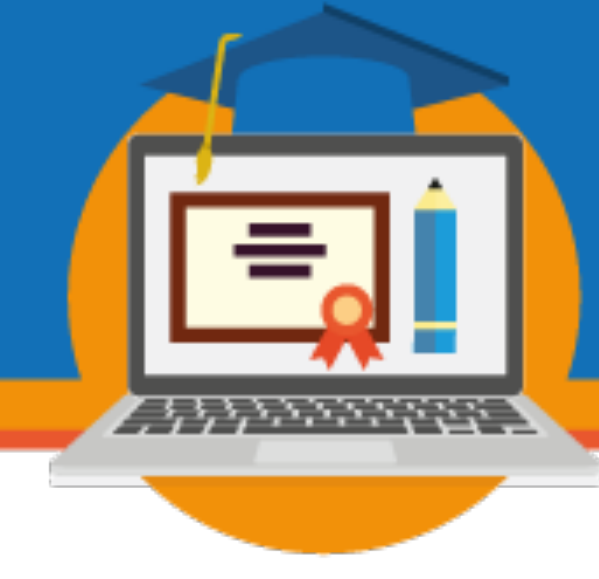

RIEDNER, Daiani Damm Tonetto Riedner. Práticas pedagógicas e tecnologias digitais no ensino superior: formação inicial de professores e inovação na UFMS. Rio de Janeiro, 2018. 185. Tese de Doutorado - Departamento de Educação, Pontifícia Universidade Católica do Rio de Janeiro. 2018.

SANTOS, Andreia Inamorato dos. Educação aberta: histórico, práticas e o contexto dos recursos educacionais abertos. In: SANTANA, Bianca; ROSSINI, Carolina; PRETTO, Nelson De Lucca. (Org.). Recursos Educacionais Abertos: práticas colaborativas políticas públicas. 1. Ed. São Paulo: Casa da Cultura Digital, 2012.p. 71-89.

SEBRIAM, Debora; MARKUN, Pedro; GONSALES, Priscila. Como implementar uma política de Educação Aberta e Recursos Educacionais Aberto (REA): guia prático para gestores. São Paulo: Cereja Editora, 2017.

UFMS. RESOLUÇÃO No 195, DE 11 DE AGOSTO DE 2017. Aprovar o Regulamento do Curso de Especialização em Mídias na Educação. Disponível em: https://sedfor.ufms.br/files/2017/08/RESOLUCAO-COPP-n-195-de-11-08-2017.pdf. Acesso em: 04 jan. 2020 